\title{
BIOCHEMICAL BASES NEEDED FOR THE MATHEMATICAL REPRESENTATION OF WHOLE ANIMAL METABOLISM
}

\author{
M. GILL, D. E. BEEVER AND J. FRANCE
}

AFRC Institute for Grassland and Animal Production, Hurley, Maidenhead SL6 5LR.

\section{CONTENTS}

\begin{tabular}{|c|c|c|c|c|c|c|c|c|c|c|c|c|}
\hline INTRODUCTION & . & . & . & . & & & $\cdot$ & $\cdot$ & $\cdot$ & . & $\cdot$ & 181 \\
\hline PRINCIPLES & . & . & $\cdot$ & . & & . & · & $\cdot$ & $\cdot$ & $\cdot$ & $\cdot$ & 182 \\
\hline OBJECTIVES & . & . & . & . & & & . & . & • & . & • & 182 \\
\hline Prediction & . & . & . & . & & & . & . & - & . & . & 182 \\
\hline Understanding & . & . & . & . & & & ${ }^{\circ}$ & - & - & ${ }^{\circ}$ & . & 183 \\
\hline HYPOTHESES & . & . & . & . & & & . & . & . & . & . & 183 \\
\hline BIOLOGICAL REP & RSE & ENT & ATIC & & & & . & . & . & . & 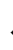 & 184 \\
\hline COMPARTMENTS & . & . & . & . & & & . & . & . & . & . & 184 \\
\hline METABOLITES & . & . & . & . & & & . & . & . & . & . & 185 \\
\hline KINETIC REPRES & NTA & ATIO & & . & & & . & . & . & . & . & 187 \\
\hline STOICHIOMETRY & & . & - & . & & & . & . & . & . & 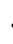 & 189 \\
\hline MODELS OF NUTR & ENT & DIG & ESTIC & & & & . & . & . & . & . & 189 \\
\hline Ruminants & . & . & . & . & & & . & . & . & . & . & 190 \\
\hline Non-ruminants & . & . & . & . & & & . & $\cdot$ & . & . & 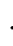 & 190 \\
\hline METABOLISM MOD & ELS & . & . & . & & & . & $\cdot$ & . & $\cdot$ & . & 192 \\
\hline PARAMETERIZAT & $1 \mathrm{ON}$ & . & . & . & & & . & . & . & . & & 193 \\
\hline DRIVING VARIAB & & . & . & . & & & . & . & . & . & & 193 \\
\hline INITIAL CONDITIC & NS & . & . & . & & & . & . & . & . & & 193 \\
\hline REACTION VELOC & & A R A & METI & ERS & & & . & & . & . & & 194 \\
\hline Affinity constants & . & . & . & . & & & . & & . & . & & 195 \\
\hline Maximum reactic & $n$ velc & ocitie & & . & & & . & & . & . & & 195 \\
\hline CONCLUSIONS & . & . & . & . & & & . & . & & . & & 196 \\
\hline REFERENCES. & . & . & . & . & & & . & . & & . & & 197 \\
\hline
\end{tabular}

\section{INTRODUCTION}

The utilization of food by an animal is dependent on the amount ingested, and the subsequent processes of digestion, absorption and metabolism. Quantification of the nutrients absorbed requires studies in vivo, while the process of metabolism has been studied through experiments conducted at the level of the whole animal, the tissue and the individual cell with the aim of understanding component parts of the overall process. As the techniques employed by researchers (and hence the quality of the information obtained) have improved, and the quantity of information available has accumulated, the desire to 
integrate this knowledge into a conceptual framework of the whole system, and hence to understand the organization of the whole animal (Milhorn, 1975), has grown. However, in order to interrelate the component parts, the framework must be quantitative and, thus, the discipline of mathematics provides an appropriate structure with which to represent the biological concepts. Such representations, in the form of an equation or a set of equations, are termed mathematical models, since solving the equations simulates the behaviour of the system. Complex models do not possess simple analytical solutions, but satisfactory numerical solutions may be generated by computer using appropriate software packages.

The application of mathematics to solving biological problems is the subject of a number of authoritative texts (e.g. Riggs, 1963; Heinrich et al. 1977; France \& Thornley, 1984) and reviews of the modelling process in relation to ingestion (Mogenson \& Calaresu, 1978), digestion (Baldwin \& Koong, 1980; Beever et al. 1986) and metabolism (Heinrich et al. 1977; Baldwin et al. 1981; Gill, 1986) have been written. In addition, the proceedings of two conferences on modelling in ruminant (Baldwin \& Bywater, 1984) and human (Canolty \& Cain, 1985) nutrition have been published recently. The aim of this review is not to restate the mathematical process of model development, but rather to describe the biochemical basis for the series of decision-making steps taken in the construction of models of whole animal metabolism. The first section considers objectives and hypotheses which have led to the development of whole animal models, while subsequent sections consider the representation of the biology and the kinetics, and the assignment of values to the parameters used in equations to calculate the transfer of matter between compartments. The emphasis is on the limits which current biochemical knowledge place on the detail with which whole animal metabolism can be represented.

\section{PRINCIPLES}

The application of scientific principles to practical problems starts by identifying goals or objectives, and proceeds through the collection of appropriate information to the generation of hypotheses. These hypotheses are then evaluated either with other published information or with findings from experiments specifically designed for the purpose, before returning to modification or updating of the objectives. The development of mathematical models contributes to this process by providing a structure within which to generate and evaluate hypotheses. Hence, mathematical modelling is simply a tool, an integral part of an experimental programme, and consequently the objectives of a model are closely related to the overall objectives of the experimental programme.

\section{OBJECTIVES}

For models of whole animal metabolism, common objectives fall into two categories which have a major influence on the representation and, thus, will be discussed under separate headings: those whose aim is to predict outputs, e.g. growth or milk production, and those whose aim is to increase our understanding of the system.

\section{Prediction}

In the livestock production industry, prediction of intake, liveweight gain and milk yield on specified diets are important components in the management of the total enterprise. Until recently, most of the models which predicted these parameters were derived by statistical resolution of large data sets (e.g. Agricultural Research Council, 1980). One disadvantage of such models is that the structure of the data set used to derive a model should be similar to the data set used for prediction. Hence as feed availability changes and 
feeding systems improve over the years, the accuracy of the original model declines and new models need to be developed. Therefore, as our understanding of the biochemistry involved has increased, there has been a move to develop models which represent the underlying processes, since this enables extrapolation of the model predictions beyond the initial data set. However, our knowledge of these processes is still far from complete and, hence, most models with the objective of prediction still consider the overall metabolism of energyyielding components and protein rather than the metabolism of the constituent biochemical compounds, for example, the models of the growing lamb by Graham et al. (1976), the growing steer by Oltjen et al. (1986) and the growing pig by Whittemore \& Fawcett (1976), Moughan \& Smith (1984) and Black et al. (1986). These models are generally based on experimental findings obtained at a whole animal level and hence, while they depend on biochemical principles, the intermediary metabolism of fat and protein synthesis are not explicitly represented and therefore the basis of such models will not be considered in this review.

On the other hand, attempts to predict the supply of absorbed nutrients in the ruminant by statistical resolution of data sets have been of limited value, and in this instance models of the underlying processes of digestion appear to be more accurate (e.g. Black et al. 1980-1; Baldwin et al. 1987 c) and will be discussed in later sections. Such models are an essential prerequisite to models of whole body metabolism, especially in ruminants.

\section{Understanding}

Concentration of research on individual components of the system, rather than on its integration, has resulted in a lack of information on many of the important mechanisms which link the component parts, and this contributes to the inability of detailed models to predict accurately, as yet. The objective of more detailed models, therefore, tends to be to increase understanding of how metabolism is integrated, but a further benefit is that their construction helps to identify gaps in current knowledge and in the design of appropriate experiments to fill those gaps (e.g. Mogenson \& Calaresu, 1978; Baldwin \& Koong, 1980; Black 1984). A number of biochemical models of whole animal metabolism have been developed since Garfinkel \& Heinmets (1969) described the potential application of computers, in their case specifically in relation to protein metabolism. The model of Schulz (1978) simulated energy balance, based on the yield and utilization of energy, for absorbed nutrients and intermediate metabolites, while Baldwin et al. (1987a) presented a model which can be used to help interpret and design energy balance experiments with dairy cows. However, in view of the limits to biochemical knowledge already specified, such models are based not only on experimental findings but also on hypotheses.

\section{HYPOTHESES}

The main hypothesis underlying models of metabolism such as those of Schulz (1978), Gill et al. (1984) and Baldwin et al. $(1987 a, b)$ is the assumption that the transfer of matter between compartments is controlled by substrate concentrations and endocrinological and neurological mechanisms. Within this overall hypothesis individual models may represent one mechanism more fully than others. For example, a major objective of the model of Gill et al. (1984) was to examine the hypothesis that the efficiency of energy retention in ruminants could be limited by the direct effect of lack of glucose precursors on the synthesis of fatty acids (MacRae \& Lobley, 1982). Control of metabolism in this model, therefore, was based entirely on substrate concentrations. Experimental evidence for the effect of changing concentrations of metabolites on rates of transfer of matter between pools can be seen in Black \& Bruss (1975). The later model of Baldwin et al. (1987b) did consider some 
effects of anabolic and catabolic hormones, but the complexity of endocrinological mechanisms has so far precluded the detailed incorporation of the effects of individual hormones in models of whole animal metabolism. The authors are also unaware of any published models which incorporate neurological mechanisms. However, it is apparent that current representation of the control of metabolism is inadequate: for example, the model of Gill et al. (1984) does not quantitatively account for all observed differences in the efficiency of energy retention in ruminants. It is hoped that more recent studies on intermediary metabolism, which attempt to identify the mechanisms controlling metabolism both within the cell and in the whole animal (Kacser \& Burns, 1973; Groen et al. 1982), will lead to the development of hypotheses which can be incorporated into future models.

\section{BIOLOGICAL REPRESENTATION}

A key step in the construction of models is to make an appropriate choice of assumptions that relate a model to the biological phenomenon under study (Greco, 1986). The first decision concerns which components to represent, where components consist both of the physical sites of reactions within the body (compartments) and the metabolic intermediates (metabolites). The choice of both types of component is dependent on the specific objective to which a model is to be addressed. In addition, the importance of individual nutrients may vary between diets consumed by different species and this will affect the choice of components represented, while the physiological state of the animal in question will influence the choice of compartments (e.g. lactating $v$. non-lactating animals).

\section{COMPARTMENTS}

Ideally the choice of which compartments to represent should be based on distinct differences in fermentation, metabolism or control of metabolism between compartments. Thus, it may be appropriate to represent cellulolytic and amylolytic bacteria separately in a model of digestion in the rumen (Baldwin et al. 1987c). However, the choice is also dependent on the objectives of the specific model. A whole animal model where the objective was to simulate fat and protein deposition in growing cattle included only three compartments, body ash, body fat, body protein together with blood pools of metabolites (France et al. 1987), while a model to study metabolism in adipose tissue took account of metabolism in the cytosol and mitochondria (Baldwin et al. 1976). These two models could both be classified as 'mechanistic' in that they simulate behaviour of a system by representing its function through elements at a lower level. This concept of level relates to the natural hierarchy of metabolism, i.e. that metabolism of the whole animal can be described in terms of metabolism of the individual organs and tissues, metabolism by the individual tissues and organs can in turn be reduced to metabolism by the cells, and metabolism by the cells can be reduced to metabolism within the cytosol and mitochondria. For a more detailed description of hierarchies, see reviews by Simon (1962) and France \& Thornley (1984).

For a 'mechanistic' model with an objective at one level, the compartments should represent the lower organizational level. However, while this suggests that a model of whole animal metabolism should be represented by metabolism of the tissues or organs, it does not resolve the question as to how many tissues or organs to represent explicitly. For example, in some whole animal models (Gill et al. 1984; France et al. 1987) body protein is represented as a single entity, in others (Baldwin et al. 1987 b; Pettigrew et al. 1989) lean body protein is separated from the viscera, while in the model of Gill et al. (1989a) ten separate tissue protein pools are represented. The basis for making these decisions largely 
relates to the specific objectives of a model. Thus, in models of the lactating animal, where lean body protein may be being mobilized during early lactation, while visceral protein may be in positive balance, there is a sound argument for separating the two pools. In other models it may be necessary to separate the liver from the gastrointestinal tract since, while level of feeding may affect both tissues, differences such as changing forage:concentrate ratio between diets for ruminants may exert a greater effect on the gut than the liver (Reynolds \& Tyrrell, 1989). Recent evidence also suggests that the effect of growth manipulants may vary between muscles (Dawson et al. 1989), and thus different muscles may need to be represented separately in models where the effects of such manipulants are to be examined.

In the model of Gill et al. (1989a), the objective was to compare, based on in vitro findings, the contribution of the energy-utilizing processes of protein turnover and ion transport in individual tissues to the heat production of the whole animal. Thus individual tissues had to be represented. However, the simulations obtained using this model demonstrated that only in the gut, liver, muscle and skin did these two processes make contributions greater than 0.05 of total heat production (Gill et al. 1989b), and in future models it may be appropriate to limit the representation to these tissues. In this example assessment of the relative contributions of the individual tissues to total heat production was one of the objectives of the model; thus it was not possible to decide in advance how many tissues should be included.

\section{METABOLITES}

It may be assumed by some that the best representation of metabolism should incorporate all known knowledge. However, as written in an Editorial to the Journal of the American Medical Association (Anon. 1960):

'A model, like a map, cannot show everything. If it did it would not be a model but a duplicate. Thus the classic definition of art as 'the purgation of superfluities' also applies to models and the model-maker's problem is to distinguish between the superfluous and the essential.'

However, even simplified models of metabolism can appear complex. Gill (1984) discussed two methods of reducing the number of metabolites which need to be explicitly represented: by assuming common pathways of metabolism for separate but closely related metabolites; or by aggregating steps of a reaction. An example of the first method, which is common to many existing models of whole animal metabolism (e.g. Gill et al. 1984; Black et al. 1986; Baldwin et al. 1987 b), is that of assuming that all amino acids are synthesized into protein or catabolized using an average stoichiometry, i.e. that the composition of the body pool of amino acids does not change. Thus, the representation is as shown in Fig. $1(a)$ (adapted from Baldwin et al. 1987b). By contrast, in a model of the lactating sow (Fig. 1(b)) the metabolism of lysine is separated from that of other amino acids. This is based on observations that lysine may be the first limiting amino acid in sow diets (e.g. Lewis \& Speer, 1973).

The second method referred to by Gill (1984) is that of reducing the number of intermediate metabolites which are explicitly represented in considering the overall pathway, i.e. aggregating steps of a reaction (for example, representing the synthesis of triacylglyceride from acetic acid as one step). Some aggregation of this type is already accepted in biochemistry (see Newsholme \& Start, 1973). Again if the objective of a model is to identify the control point of a pathway such a representation is not appropriate, but for calculating the flux of say carbon through the pathway, provided the parameters reflect 
(a)

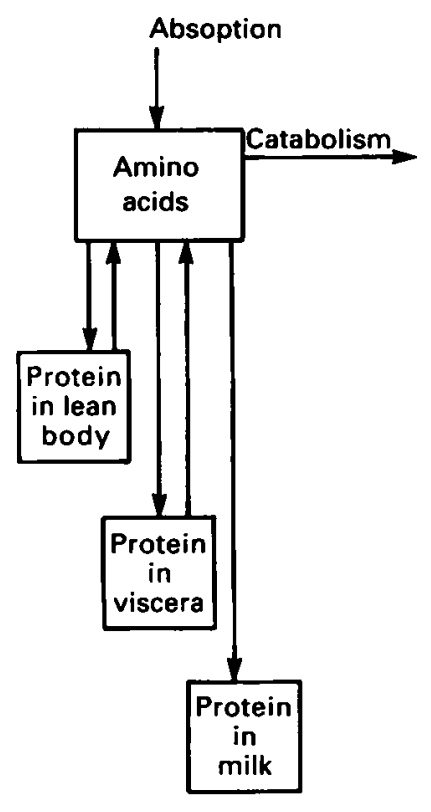

(b)

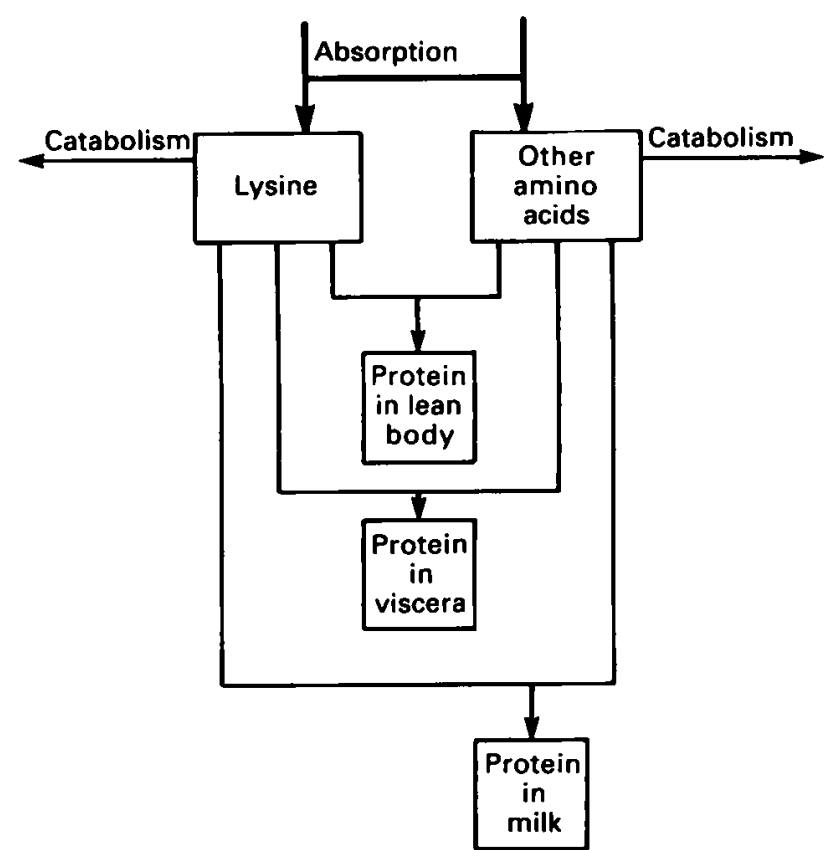

Fig. $1(a)$. Diagram representing amino acid metabolism in the lactating cow (adapted from Baldwin et al. 1987 b); (b) diagram representing amino acid metabolism in the lactating sow (adapted from Pettigrew et al. 1989).

the main limits to the overall rate, the general behaviour of the system can be modelled. This leads us to a discussion on how to decide which intermediates are essential.

One possible method on which to base this decision might be the identification of ratelimiting enzymes, using the concept of control strength (Higgins, 1965; Kacser \& Burns, 1973), that is 'the fractional change in flux through a pathway, induced by a fractional change in the activity of the enzyme catalysing that step' (Groen et al. 1982). Theoretically, therefore, intermediates identified as having high control coefficients could be included in models. However, in considering the metabolism of the whole animal some intermediates may participate in a number of pathways, and some of these pathways may operate in different compartments. Hence, while it may be possible to use control coefficients as measures of control in limited systems (Groen et al. 1982), in more complex systems such as the animal as a whole this approach appears to be unsatisfactory (Crabtree \& Newsholme, 1987). There is one intermediate, however, whose controlling effect has been identified (Atkinson, 1968) and whose role in metabolism is central; that is ATP. The identification of ATP as the main carrier for the transfer of chemical energy between reactions was, in fact, a key step in the development of models of whole body metabolism (Baldwin \& Smith, 1975).

Decisions on other metabolites to include in a model are more subjective, although dependent on the specific objective. One method of trying to achieve some form of standardization between models is to start from the desired outputs, derive the relevant precursors and the metabolites likely to exert an influence on the reaction rates, compare these with the known inputs, and then decide according to the previously mentioned aggregation processes which metabolites can be omitted without prejudicing the behaviour of the model. This process can include a study of the results of tracer kinetic experiments, 
where the transfer of, for example, carbon between metabolites is quantified. Some metabolites may need to be included within a model in order to fulfill stoichiometric relationships, but if their utilization is assumed to equal their production, then such pools can be represented as zero or constant pools (Baldwin et al. 1987 b).

\section{KINETIC REPRESENTATION}

Once the biological representation has been decided on, mathematical equations must be written. Since these equations are solved to calculate the rate of change in size of various pools of the system, time is an essential component, i.e. the model is dynamic. The standard mathematical way of presenting dynamic, mechanistic models, is called the rate:state formalism, which can be described as follows. At time, $t$, the system is defined by $q$ state variables (the compartment and metabolite pools) : $Q_{1}, Q_{2}, \ldots, Q_{q}$. The model then consists of $q$ first order differential equations which describe how these state variables change with time:

$$
\begin{aligned}
& d Q_{1} / d t=f_{1}\left(Q_{1}, Q_{2}, \ldots, Q_{q}\right), \\
& d Q_{2} / d t=f_{2}\left(Q_{1}, Q_{2}, \ldots, Q_{q}\right), \\
& d Q_{q} / d t=f_{q}\left(Q_{1}, Q_{2}, \ldots, Q_{q}\right) .
\end{aligned}
$$

The terms on the right-hand side are simply the inputs to and outputs from each pool. These inputs and outputs are based on equations which are dependent on the values of the state variables. Since the transfer of matter between metabolite pools is mediated through enzymes which catalyse specific reactions, it is appropriate to represent the process using standard enzyme and chemical kinetics. The differential equations are formed through the direct application of physical and chemical laws, such as the first law of thermodynamics and the law of conservation of mass, in that all matter and energy in the transactions must be accounted for.

The velocity equations of chemical and enzyme kinetics are all variants or extensions of five basic forms: (1) the mass action equation, (2) the rectangular hyperbola of Michaelis and Menten, (3) the sigmoidal Hill equation of allosteric enzyme kinetics, (4) the competitive, (5) the non-competitive equation for simple inhibition systems (for a derivation of these forms, see Mahler \& Cordes, 1971; Segel, 1975). Such kinetic representations are not confined to physical chemistry and enzymology. These equations, with only slight modifications, are directly applicable to studies of drug and hormone binding to receptor sites, and they are the basis of the study of the movement of molecules and ions across cell membranes (Christensen, 1975; Stein, 1986). The Michaelis-Menten equation, for example, describes active transport for a unidirectional flux. They are also central to the kinetics of microbe and cell cultivation (Pirt, 1975). The Monod equation for microbial growth, for example, is a rectangular hyperbola identical to the MichaelisMenten equation. Such kinetic representation is not confined to events at the molecular and cellular level. Mass-action forms are adopted in methods for calculating protein turnover in the whole animal and in specific tissues (Waterlow et al. 1978; Garlick, 1980). Indeed, they underlie most in vivo tracer kinetic methods (Shipley \& Clark, 1972). Michaelis-Menten equations describe the ability of a tissue and whole animal to oxidize or otherwise utilize specific metabolites (e.g. Baldwin et al. 1980). The generalized saturation kinetic function (Mercer $e t$ al. 1978), which is a reparameterization of the Hill equation, has been widely used as a nutrient response function to relate weight gain to intake.

Thus, reaction velocity representation (v) throughout animal biology and biochemistry has its roots in chemical and enzyme kinetics. General expressions can be written such as the forms:

$$
v=k\left[\mathrm{~S}_{1}\right]^{N_{1}}\left[\mathrm{~S}_{2}\right]^{N_{2}} \ldots,
$$




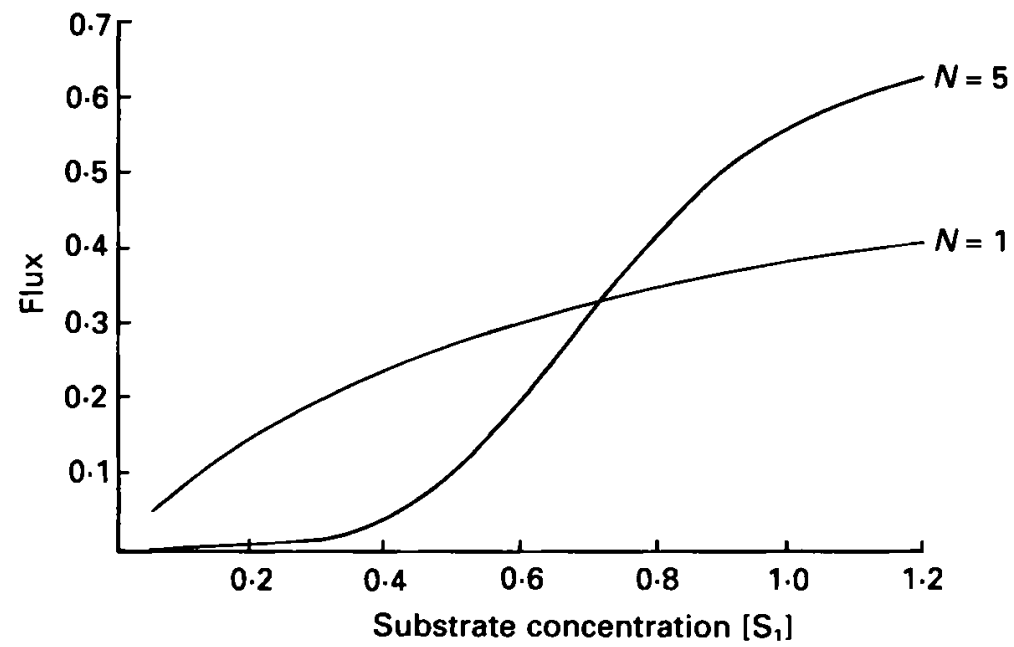

Fig. 2. Effect of changing the value assigned to the exponent $(N=I$ and $N=5)$ in equation of form (2)

$$
\text { Flux }=V_{\max } /\left\{1+\left(K_{1} /\left[S_{1}\right]\right)^{N}\right\} .
$$

and

$$
v=V_{\max } /\left\{1+\left(K_{1} /\left[\mathrm{S}_{1}\right]\right)^{N_{1}}+\left(K_{2} /\left[\mathrm{S}_{2}\right]\right)^{N_{2}}+\ldots+\left(\left[\mathrm{I}_{1}\right] / \mathrm{J}_{1}\right)^{M_{1}}+\left(\left[\mathrm{I}_{2}\right] / \mathrm{J}_{2}\right)^{M_{2}}+\ldots\right\},
$$

where $V_{\max }$ is the maximum value of $v, \mathrm{~S}_{1}, \mathrm{~S}_{2} \ldots$ are individual substrates, $K_{1}$, $K_{2} \ldots$ corresponding Michaelis-Menten constants, $I_{1}, I_{2} \ldots$ individual inhibitors, $J_{1}$, $\mathrm{J}_{2} \ldots$ corresponding inhibition constants and $N_{1}, N_{2} \ldots$ and $M_{1}, M_{2} \ldots$ are steepness parameters. These expressions seem to be appropriate in mechanistic models of whole animal metabolism which require kinetic representation of events occurring at the tissue and organ level. Changing the values assigned to $N$ and $M$ can alter the shape of the rate versus. concentration relationship and, thus, appropriate values may be chosen to ensure that the curves more closely resemble the results of experimental observations. This effect is illustrated in Fig. 2.

Such expressions have several attractive features for the partitioning of nutrients between fluxes in a mechanistic model, for example:

(1) all the parameters are in units of velocity or concentration and can thus be ascribed biological meaning;

(2) the affinity constants $(K)$ reflect priorities between fluxes for a particular substrate, e.g. if more than one flux utilizes the same substrate then the flux which has the highest priority for that substrate will have the smallest $K$ value in its reaction velocity equation; and

(3) hormonal influences can be mediated through changes in $K$ and $V_{\max }$ (Yang \& Baldwin, 1973), with rising levels of anabolic hormone concentration decreasing $K$ and rising levels of catabolic hormone concentration increasing $V_{\max }$. Baldwin et al. (1987b), modelling dairy cow metabolism, simply represented hormonal activity in terms of changes in glucose concentration [Gl], with

and

$$
\begin{gathered}
K=K_{0}\left([\mathrm{Gl}]_{0} /[\mathrm{Gl}]\right)^{N_{1}}, \\
V_{\max }=V_{0}\left([\mathrm{Gl}]_{0} /[\mathrm{Gl}]\right)^{N_{2},}
\end{gathered}
$$

where $K_{0}$ and $V_{0}$ are the values of $K$ and $V_{\max }$ when glucose concentration assumes its reference level [Gl $]_{0}$, and $N_{1}$ and $N_{2}$ are steepness parameters. 
The animal modeller working at the tissue and whole animal levels, however, should not regard equations such as 1 and 2 as being truly mechanistic since complete justification at the lower levels may be lacking, and parameter values may not be derivable from more fundamental considerations. Thus, for example, while the control of protein metabolism in tissues other than the liver may be mainly hormonal (Young, 1980), the relationship between diet and endocrine status is not as yet well understood. One possibility discussed by Lindsay (1983) is that amino acid intake stimulates the endocrine response. The concentration of metabolites may therefore be used to simulate the effects of hormones until our understanding is sufficient to quantify the true representation.

In modelling metabolic and endocrine systems in human physiology and clinical medicine the hyperbolic tangent function is generally used to aggregate a number of enzyme-catalysed reactions into a single equation (e.g. Corbelli et al. 1980; Corbelli \& Mari, 1983). The justification for this sigmoidal function is essentially empirical in that it well represents the threshold and saturation behaviour typically observed with multienzyme pathways. Hormonal effects are incorporated into this form as a change in the saturation value and in the slope of the equation. The mathematical properties of the hyperbolic tangent are described in Abramowitz \& Stegun (1965). Other functional forms used for representing a reaction velocity subject to active hormonal control are the proportional plus derivative form used by Licko (1973) in modelling threshold secretory mechanisms; the bilinear relation used by Bergman et al. (1979) in modelling glucose disappearance; the Langmuir equation described by Brown (1980).

Each equation thus represented within a model contains a number of parameters. Mechanistic simulation models of whole animal metabolism, by their very nature in representing a complex system, tend to be large and thus to contain a large number of parameters, and for the purposes of this review the assigning of values to these parameters will be discussed in two sections : firstly, the stoichiometric or yield and requirement factors, and secondly the parameters which determine the exogenous inputs to the model, the initial size of the pools and the velocity equation parameters which determine the rate of transfer of matter.

\section{STOICHIOMETRY}

Stoichiometry is the branch of science which defines the laws of chemical reactions in quantitative terms. In mathematical models of digestion and metabolism, stoichiometry is used to define yield and requirement factors for the transfer of $\mathrm{C}$, nitrogen and other elements between substrates and products, with due recognition of energy requirements or yields within the reaction. However, while at an enzyme level the quantitative relationships for $\mathbf{C}$ and $\mathbf{N}$ transfer are generally well-defined, the presence of a variety of microbial species within the alimentary tract or alternative pathways for metabolism in the tissues can result in variable relationships in aggregated models. It is these variable relationships which form the main subject matter of this section.

\section{MODELS OF NUTRIENT DIGESTION}

Models of nutrient digestion are required as the first stage in models of whole animal metabolism. They convert the feed inputs into the nutrients absorbed from the gastrointestinal tract, which thus become available to the tissues. As a consequence of the type of diet consumed and the presence of a large mixed population of microbes in the rumen this process is obviously more complex in ruminants than non-ruminants; the two species will therefore be discussed separately. 


\section{Ruminants}

In the most simplified but highly controlled in vitro fermentation system employing a defined pure microbial culture it is possible to ferment $1 \mathrm{~mol}$ glucose and accurately estimate the yields of acetate, propionate, butyrate and methane. Altering the microbial inoculum or introducing a mixed microbial population will change this relationship, and further changes in product yields will occur when mixed carbohydrate sources are used. Increasing the rate of fluid turnover in a continuous fermentation system is known to shift end-product formation (Pirt, 1975). Furthermore, when the pattern of feeding is disturbed, as occurs in the animal, the relationships between substrates, microbial inoculum and products will be perturbed as the partition between hexose fermentation for ATP production, with volatile fatty acids (VFA) as an important by product, and direct use of hexose for microbial growth will change (Beever et al. 1980-1). In such situations choice of the most suitable stoichiometric relationships to include in a model will depend on the level at which the specific model is being developed. Where the aim of the rumen model is to provide profiles of absorbed nutrients as inputs to metabolism models (e.g. Baldwin et al. 1987 c) the quantitative yields of VFA are important; thus it is necessary to provide the most precise relationships between hexose fermentation and VFA production. Clearly if subsequent examination of the behaviour of a particular model indicates that some of these assumptions are in error, then further consideration of the stoichiometric relationships will be necessary. In other situations, the need for such representations will be less demanding.

The current position regarding stoichiometric relationships between hexose and protein degradation and VFA production in the rumen was recently reviewed by Murphy (1984). Based on a large number of in vivo observations, Murphy (1984) applied a range of mathematical procedures in order to obtain best-fit solutions, which are summarized in Table 1. This indicates a broad categorization into four substrates (soluble carbohydrate, starch, hemicellulose and cellulose) and two diet types (forages and concentrates), although Murphy (1984) did stress that this analysis may, in the long term, prove to be an oversimplification. However, this rationalization by Murphy (1984) has proved useful and has contributed to the improved accuracy of prediction of nutrient supply observed in the model of Baldwin et al. (1987 c) compared to earlier attempts (Baldwin et al. 1977; Black et al. 1980-1).

\section{Non-ruminants}

In non-ruminants, the changes to the ingested nutrients during digestion are generally the result of gut enzymes rather than microbial enzymes, and consequently the nutrients absorbed are more similar to those ingested than in the ruminant animal. However, with increased interest in feeding fibre to non-ruminants, e.g. to pigs (Longland et al.1989), caecal fermentation now makes a significant contribution to total absorbed nutrient supply. Since caecal fermentation is also microbial in nature, accounting for these conversions will be subject to similar problems as discussed earlier in relation to fermentation in the rumen. In addition, the yield of nutrients may be affected by level of feed intake and rate of propulsion of digesta along the alimentary tract (Fioramonti \& Bueno, 1988). To date, the authors are unaware of any attempt to construct a model to predict nutrient supply in non-ruminants, but the need for such a model was demonstrated in the limitations which had to be imposed on the sow model developed by Pettigrew et al. (1989), in that it cannot as yet be used to simulate the results of feeding sows high-fibre diets. 


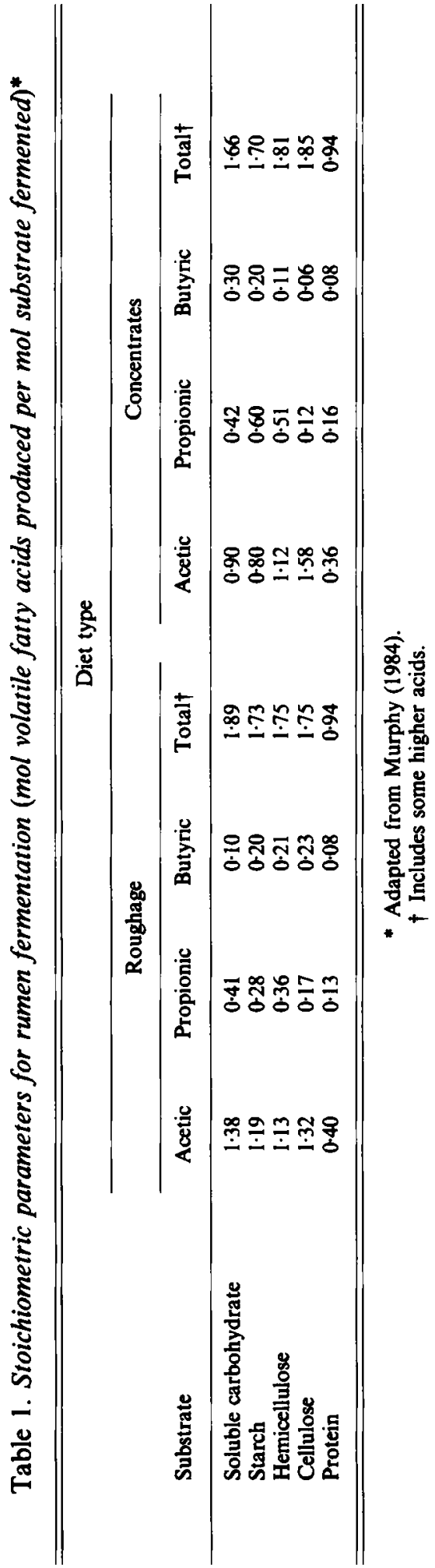




\section{METABOLISM MODELS}

Research over the last 30 years or so has elucidated many of the reactions involved in the metabolism of absorbed nutrients within the tissues of the animal, and several textbooks which detail the stoichiometries of individual pathways are available (e.g. Mahler \& Cordes, 1971). Thus, for example, the complete aerobic oxidation of glucose through glycolysis may be represented as:

$$
\mathrm{C}_{6} \mathrm{H}_{12} \mathrm{O}_{6}+6 \mathrm{O}_{2}+38 \mathrm{ADP} \rightarrow 6 \mathrm{CO}_{2}+6 \mathrm{H}_{2} \mathrm{O}+38 \mathrm{ATP} \text {. }
$$

This assumes that regeneration of 1 mol NAD from NADH yields 3 mol ATP, by taking mitochondrial oxidation of NADH into account (Newsholme \& Start, 1973). If this is not accounted for, the yield of ATP from 1 mol NADH is 2 and the total yield of ATP from 1 mol glucose is $34 \mathrm{~mol}$. Further, with reference to glycogen oxidation, whilst muscle glycogen reserves in most animals are generally low, they can provide short bursts of readily available energy. Under fully aerobic conditions, oxidation of $1 \mathrm{~mol}$ glucose equivalents present as glycogen in muscle will provide the $38 \mathrm{~mol}$ ATP referred to previously, but studies of energy utilization during exercise have revealed that glycogen metabolism invariably precedes stimulation of blood supply to the muscles, and consequently a large proportion of the glycogen may be degraded anaerobically yielding only $10 \%$ of the ATP yield under fully aerobic conditions (Newsholme \& Start, 1973; Lister, 1989).

Another complication in considering the metabolism of glucose, which again alters the yield of ATP, relates to its oxidation through the pentose phosphate pathway for the generation of NADPH. Partitioning of glucose between the glycolytic and pentose phosphate pathways might be achieved on the basis of perceived NADPH requirement, but there is evidence that in some tissues NADPH can be generated from acetyl CoA via the isocitrate dehydrogenase (EC 1.1.1.42) pathway (Ballard et al. 1969). The factors which control the initiation and extent of this route of NADPH production are not known, but in those situations where it is likely to occur, albeit to a varying extent, it is difficult to establish a constant stoichiometry for glucose oxidation. In the model of sheep growth by Gill et al. (1984), one of the major objectives was to examine the cause of low efficiencies of energy utilization on forage diets and, hence, both routes of NADPH generation were included. In other situations, where the objective is different and the level of aggregation greater, it may be sufficient to consider that the isocitrate dehydrogenase pathway does not make a significant contribution to overall energy utilization and thus can be ignored. These considerations in relation to glucose metabolism highlight the oversimplification which may occur in assuming constant stoichiometries for metabolism of certain intermediates.

A further aspect which may affect stoichiometric relationships relates to the assumption of common pathways for amino acid metabolism, as referred to earlier. Schulz (1978) provided an excellent review of the stoichiometry of individual amino acid metabolism and this has been adapted for different species on the basis of the ratios of individual amino acids absorbed (e.g. for sheep Gill et al. 1984; for sows Pettigrew et al. 1989). However, preferential utilization of amino acids by individual organs, e.g. Bergman \& Pell (1984), may substantially change the composition of amino acids which are ultimately available for muscle protein synthesis, and consequently lead to the need for a fuller consideration of the composition of the individual amino acids.

One further area of concern with respect to amino acid metabolism relates to the energy costs of protein synthesis and turnover. Most estimates of peptide bond synthesis indicate an energy cost of $5 \mathrm{~mol}$ ATP per peptide bond, incorporating the use of 2 mol ATP for amino acid activation; $2 \mathrm{~mol}$ GTP for peptide bond synthesis and elongation, with a further 1 mol ATP to cover transport costs. In contrast, Siems et al. (1984) reported a value 
of 3 mol per peptide bond, whilst Appanna et al. (1984) obtained a stoichiometric relationship of 2 mol ATP per peptide bond synthesized in a cell-free system of Aerobactor aerogenes. Equally, in a recent study with growing pigs Reeds et al. (1985) reported an apparently higher total energy cost of protein synthesis. Reeds et al. (1987) quantified this cost as an additional 3.3 units increase in total energy expenditure per unit increase in energy directly expended in protein synthesis. However, this relationship requires further investigation. The situation is further confused by observations that peptide bond cleavage may have a significant and variable energy cost (for review, see Summers et al. 1988). The quantitative significance of the assumptions related to these stoichiometries can be examined in specific models developed for that purpose (e.g. Gill et al. 1989b), but fixed assumptions need to be made for incorporation in models of whole animal metabolism.

\section{PARAMETERIZATION}

Apart from the specific problems of variable stoichiometries discussed in the previous section, stoichiometric parameters tend to have a general application across species. The parameters to be described in this section are species-specific or even, in the case of driving variables and initial conditions, diet-specific and the values assigned are therefore obtained from the results of well-defined experiments.

\section{DRIVING VARIABLES}

Driving variables are the exogenous inputs to a model, e.g. in a digestion model they represent the intake of feed and its component parts, while in a metabolism model they represent the absorption of nutrients. In highly aggregated models (e.g. Moughan \& Smith, 1984; Black et al. 1986) nutrient inputs are expressed in terms of energy and $\mathrm{N}$, while in more detailed representations of digestion (e.g. Baldwin et al. 1977, 1987c; Black et al. 1980-1), feed dry matter is described in terms of a large number of chemical constituents. On the other hand, detailed metabolism models require partition of absorbed energy and $\mathrm{N}$ into amino acids, glucose, VFA and fatty acids (Gill et al. 1984; Baldwin et al. 1987b; Pettigrew et al. 1989). These values are not an integral part of a model, but change according to the experimental conditions of the data to be simulated. While it might appear that such values should be readily obtainable from the literature, in practice very few papers characterize all the feed or absorbed energy in terms of its constituent parts. Thus, there may be details of the $\mathbf{N}$ fractions of feed for one experiment, and details of the carbohydrate fraction in another. Where complete profiles of absorbed nutrients are available these generally correspond to one feeding level, which ignores the possibility that there may be an interaction between level of feeding and the profile of nutrients absorbed, although it may be possible to derive relationships between flow of nutrients into the duodenum and intake in the diet (see Ulyatt et al. 1984). Where data on nutrient profiles do exist they have generally been obtained in a digestion experiment, and the availability of corresponding data, on the same diets, on metabolism or protein and fat deposition is rare. Data of this type are required for model parameterization and evaluation.

\section{INITIAL CONDITIONS}

State variables define or help to define the state of the system at any given time. Thus, in a model of animal metabolism (e.g. France et al. 1987) both the body protein and body fat pools and the amount of acetate or other intermediates in the blood are termed state variables. These variables are quantities, in units of, for example, $\mathrm{g}$ or mol, and integration 
of the differential equation for each state variable updates the size of the pool at each iteration. The initial values of the state variables are a characteristic of the data set to be simulated. However, within a limited range, if a model is run for a sufficient period of time, the final output should be relatively independent of the initial values ascribed to the size of the pools, provided the model is stable. In digestion models initial values can be calculated from the concentrations of metabolites in the rumen or stomach by assuming a value for the volume of the compartment. For metabolism models carcass values provide reliable values for the size of the body compartments, and it is largely quantification of the metabolite pools which presents a problem. This is particularly true of aggregated models where the acetate pool, for example, has to be representative of reactions occurring in the liver, muscle and adipose tissue. In vivo, it is generally the intracellular concentrations of metabolites which function as modifying factors of the reaction rates, and this may differ between compartments (Lunn et al. 1976). In addition, with respect to protein synthesis, it is not yet known whether the true precursor pool is intra- or extracellular (McNurlan et al. 1979). At present, approximate values for concentrations have to be assumed, and in most whole animal models published to date metabolite pools are represented as blood or plasma concentrations. Some justification for the acceptability of this approach can be seen in the outputs from the model of Baldwin et al. $(1987 \mathrm{~b})$. During sensitivity analysis where some of the parameters of the model were perturbed, simulated blood acetate and glucose concentration changes lay within the normal range.

This approach of using blood concentrations as surrogates for intracellular concentrations may be acceptable for metabolites present in millimolar amounts, but is not possible for state variables such as ATP and NADPH. These factors are present at very low concentrations (Reich \& Sel'kov, 1982) and multiplication of these concentrations by metabolic volumes to give pool sizes still results in small pools, relative to their rate of turnover. This can lead to computational problems when models parameterized to examine metabolism over a short time-interval (e.g. within $1 \mathrm{~d}$ ) are extrapolated to simulate longer time-intervals (e.g. complete lactations) (Baldwin et al. 1987a).

\section{REACTION VELOCITY PARAMETERS}

While the state variables change between iterations of a model, the parameters determining reaction velocities, apart from substrate concentrations and size of compartments, remain constant. As these parameters are involved in determining the rate of exchange of energy or matter between pools, assigning of values to them is an important step in constructing any model. Since the mathematical representation of a model is based on enzyme kinetics, it might be assumed that values from in vitro enzyme experiments might be used. However, while much work has been done in recent years to characterize enzymes and obtain values for maximum velocities and affinity constants from in vitro experimentation, such experimentation is carried out under defined conditions in the laboratory. The problem in assigning parameter values is to relate the conditions of incubation to the conditions experienced by the microbes or tissues in vivo. For example, the rates of fermentation of substrates by a single microbial species are very different from those observed in a mixed culture (Church, 1970), while with in vitro tissue studies the presence or absence of hormones in the media can alter adipose tissue metabolism (Christie, 1981). Hence, in order to obtain compatible data sets for building models of whole animal metabolism, data obtained under similar incubation conditions must be used.

In general, most laboratories work on isolated aspects of metabolism; hence, data sets applicable to the whole animal are not available. However, Baldwin's group in California, after being unable to obtain sufficient data on adipose metabolism for accurate 
representation in a model of a dairy cow (Smith, 1970), conducted in vitro experiments and developed a model of adipose tissue (Baldwin et al. 1976). This subsequently led to the development of an improved model of the lactating cow (Baldwin et al. 1987a-c). This model demonstrates that sensible representations of whole animal metabolism can be developed from in vitro kinetic experiments with tissue slices and isolated cells, and illustrates the cycle from development of hypotheses, through designing and conducting appropriate experiments, to evaluation and modification of hypotheses in a further model.

Where data of this nature are not available, an alternative approach to assigning parameter values must be sought. For models of whole animal metabolism, one source is flux data possibly determined using isotope-dilution techniques. The type of parameters required depends on the choice of kinetic representation (see p. 187-189) but will be discussed here in terms of affinity and inhibition constants, maximum velocities, and steepness parameters. Ideally such parameters would be estimated from the flux data using nonlinear regression (Draper \& Smith, 1981). In reality, however, the data are seldom of sufficient quantity and resolution to permit statistical estimation. This is not the major limitation it is sometimes perceived to be, as mechanistic models are not usually developed entirely to address problems of practical prediction, but rather to evaluate current understanding for adequacy and, when current understanding is inadequate, help identify critical experiments. In the remainder of this section, therefore, parameter assignment is confined to situations which do not lend themselves to statistical estimation.

\section{Affinity constants}

These constants account for the fact that the rate of the reaction will decrease as the concentration of substrates decreases, while inhibition constants represent feedback inhibition when the concentration of product is high. In models of whole animal metabolism where concentrations depicted represent blood concentrations, which differ from those used in in vitro incubations, as discussed earlier, it is generally not possible to use values determined in vitro. One alternative is to assign values within an appropriate range on a priority basis, given experimental observations of the priority of different reactions for the same substrate. As referred to in the kinetics section, the lowest value for an affinity constant for any one substrate gives that reaction the highest priority for that substrate. For inhibition constants the opposite is true, i.e. where a particular metabolite limits more than one reaction, the higher the value assigned to the inhibition constant in any reaction the greater the relative inhibition. As discussed in the kinetics section these constants may be modulated through the inclusion of steepness parameters which produce a sigmoidal effect.

\section{Maximum reaction velocities}

The maximum velocity of an enzyme-based reaction is dependent on both the amount and the activity of enzyme present. In dynamic models the physiological state of the animal is changing, which presumably affects the enzyme activity and consequently the maximum reaction velocity, while very few in vitro studies have been conducted on sequential samples taken during growth or lactation. A simple way of representing this within a model is to include an auxiliary equation to modify the maximum velocity per $\mathrm{g}$ tissue by the size of the tissue or organ in which the enzyme is located. For example, for gluconeogenesis from propionate, which is assumed to occur only in the liver of ruminants, the $V_{\max }$ for the reaction would be scaled by liver weight. However, the rates of some reactions are not simply a linear function of tissue weight, but may in fact decline with degree of maturity, e.g. protein synthesis. This can be represented by including a parameter related to mature protein weight. Inclusion of this term takes some account of the potential of the animal as 
defined by breed, a point which was emphasized by Oldham \& Emmans (1988). Another method for accounting for breed differences was illustrated by Oltjen et al. (1986), who incorporated a DNA pool in their model to predict growth in beef cattle. However, it is still difficult to determine true maximum reaction velocities experimentally, since most experiments are likely to have been conducted under nutritionally limiting conditions. Further problems also exist in trying to select rates for protein synthesis and degradation, owing to the problem of deciding which is the true precursor pool. Some earlier reports give different estimates of the fractional rate-constant derived from different free pools (e.g. Lobley et al. 1980), and while this problem has apparently been resolved for measurements in small laboratory animals (McNurlan et al. 1979), there is still a lack of data using this technique with farm animals.

One method of assigning values to maximum velocities is to define a particular set of experimental results in terms of the utilization of a substrate in a reaction and the concentrations of substrates; to attribute values to the affinity constants as discussed previously and, hence, to solve the equations numerically for the maximum velocity. A comparison of this value with in vitro values then helps in the decision as to whether this method is appropriate for that particular reaction. This was the approach adopted by Pettigrew et al. (1989).

In some aspects of metabolism there is very little information with which to develop a mechanistic representation. One such area is the utilization of energy to maintain bodyweight, or 'maintenance' energy expenditure. Many studies have investigated individual processes which contribute to the overall expenditure, but at present no attempt to sum all the component processes (e.g. Milligan, 1971 ; Baldwin et al. 1980; Summers et al. 1988) has equated with more empirical assessments (e.g. Agricultural Research Council, 1980).

\section{CONCLUSIONS}

No model yet exists which can accurately simulate whole animal metabolism in all circumstances. This paper has reviewed some aspects of digestion and metabolism, both where current understanding appears to be adequate and where the representation used so far is a gross simplification of the animal system, owing to lack of biochemical knowledge. This is particularly true with respect to the representation of the control of metabolism. Current models have placed considerable emphasis on partitioning nutrients according to substrate concentration and, while an empirical representation of endocrine control has been included in recent lactation models (Baldwin et al. 1987a; Pettigrew et al. 1989), this is an area which merits further study. The development of models of individual compartments may be one means by which hypotheses relating to such control may be studied, and while some organ models do already exist (e.g. metabolism by the mammary gland of the lactating cow (Waghorn \& Baldwin, 1984), ruminant adipose tissue (Baldwin et al. 1976) and transport across the gut wall (Heidegar \& Ferguson, 1985)), the authors are not aware of any published models on metabolism in the liver or gut of farm animals. Current experimental work in intermediary metabolism is tending to move away from measurement at a whole animal level, and is concentrating more on the metabolism of individual tissues through the use of arterio-venous techniques. Such information will be of considerable value to those attempting to develop models, but the usefulness of such findings would be much improved if (a) the values were accompanied by details on the physiological and nutritional status of the animal, including composition and quantity of feed ingested and composition of gain or milk produced, and (b) if the analyses undertaken aimed to account for the majority of the nutrients which make a significant contribution to the metabolism of the tissue in question. 
The lack of information which completely defines either the composition of feed (digestion models) or the profile of nutrients absorbed (metabolism models) precludes the utilization of many experimental results in the development or evaluation of models. The current trend to more complete analysis of the carbohydrate fraction of feeds (e.g. McAllan et al. 1988) does help in this respect, but only if it is complemented by studies on the digestion, absorption and utilization of the additional fractions.

There is also a need for improved characterization of animals used in experiments. For subsequent utilization of the information in model construction this may simply require determination of the total protein or fat in the carcass but, dependent on the objective of the specific model, it may be necessary to extend such studies to consider visceral and lean body pools and even different muscle types. A large body of information on carcass composition and the weights of individual organs does exist, but the most thorough experiments in this regard were undertaken some years ago, and livestock breeding programmes have undoubtedly changed the composition of modern breeds. Such information on dairy cows is particularly scarce.

It has been stated that computer simulation will become increasingly necessary in biomedical research (Kootsey, 1986) in order to cope with the increasing complexity of hypotheses. The present review has assumed that the same is true for whole animal metabolism and has tried to demonstrate the type of approach required. In summary, progress in mathematical representation of whole animal metabolism will only be achieved through integrated programmes of experimental work and modelling which will involve collaboration and positive commitment between research groups and between researchers with expertise in different disciplines.

\section{REFERENCES}

Abramowitz, M. \& Stegun, I. A. (editors) (1965). Handbook of Mathematical Functions. New York: Dover Publications.

Agricultural Research Council (1980). The Nutrient Requirements of Ruminant Livestock, 2nd ed. Farnham Royal: Commonwealth Agricultural Bureaux.

Anon. (1960). Editorial. Journal of the American Medical Association 174, 407-408.

Appanna, D. L., Grundy, B. J., Szczepan, E. W. \& Viswanatha, T. (1984). Aerobactin synthesis in a cell-free system of Aerobacter aerogenes 62-1. Biochimica et Biophysica Acta 801, 437-443.

Atkinson, D. E. (1968). The energy charge of the adenylate pool as a regulatory parameter. Interaction with feedback modifiers. Biochemistry 7, 4030-4034.

Baldwin, R. L. \& Bywater, A. C. (editors) (1984). Modelling Ruminant Digestion and Metabolism, Proceedings of the 2nd International Workshop. Davis, CA: University of California.

Baldwin, R. L., Crist, K., Waghorn, G. \& Smith, N. E. (1981). The synthesis of models to describe metabolism and its integration. Proceedings of the Nutrition Society 40, 139-145.

Baldwin, R. L., France, J., Beever, D. E., Gill, M. \& Thornley, J. H. M. (1987a). Metabolism of the lactating cow. 3. Properties of mechanistic models suitable for evaluation of energetic relationships and factors involved in the partition of nutrients. Journal of Dairy Research 54, 133-145.

Baldwin, R. L., France, J. \& Gill, M. (1987 b). Metabolism of the lactating cow. 1. Animal elements of a mechanistic model. Journal of Dairy Research 54, 77-105.

Baldwin, R. L. \& Koong, L. J. (1980). Mathematical modelling in analyses of ruminant digestive function: philosophy, methodology and application: In Digestive Physiology and Metabolism in Ruminants, pp. 251-268 [Y. Ruckebusch and P. Thivend, editors]. Lancaster: MTP Press.

Baldwin, R. L., Koong, L. J. \& Ulyatt, M. J. (1977). A dynamic model of ruminant digestion for evaluation of factors affecting nutritive value. Agricultural Systems 2, 255-288.

Baldwin, R. L. \& Smith, N. E. (1975). Molecular control of energy metabolism. In The Control of Merabolism. pp. 17-34 [J. D. Sink, editor]. University Park, PA: Pennsylvania State University Press.

Baldwin, R. L., Smith, N. E., Taylor, J. \& Sharp, M. (1980). Manipulating metabolic parameters to improve growth rate and milk secretion. Journal of Animal Science 51, 1416-1428.

Baldwin, R. L., Thornley, J. H. M. \& Beever, D. E. (1987c). Metabolism of the lactating cow. 2. Digestive elements of a mechanistic model. Journal of Dairy Research 54, 107-131.

Baldwin, R. L., Yang, Y. T., Crist, K. \& Grichting, G. (1976). Theoretical model of ruminant adipose tissue metabolism in relation to the whole animal. Federation Proceedings 35, 2314-2318. 
Ballard, F. J., Hanson, R. W. \& Kronfeld, D. S. (1969). Gluconeogenesis and lipogenesis in tissue from ruminants and nonruminants. Federation Proceedings 28, 218-231.

Beever, D. E., Black, J. L. \& Faichney, G. H. (1980-1). Simulation of the effects of rumen function on the flow of nutrients from the stomach of sheep. 2. Assessment of computer predictions. Agricultural Systems 6, $221-241$.

Beever, D. E., France, J. \& Theodorou, M. K. (1986). Modelling of rumen function. In New Developments and Future Perspectives in Research on Rumen Function, pp. 109-140 [A. Neimann-Sorenson, editor]. Brussels: EEC.

Bergman, E. N., Ider, Y. Z., Bowden, C. R. \& Corbelli, C. (1979). Quantitative estimation of insulin sensitivity. American Journal of Physiology 236, E667-E677.

Bergman, E. N. \& Pell, J. M. (1984). Integration of amino acid metabolism in the rumen. In Herbivore Nutrition in the Subtropics and Tropics, pp. 613-628 [F. M. C. Gilchrist and R. I. Mackie, editors]. Craighall, South Africa: Science Press.

Black, A. L. \& Bruss, M. L. (1975). Present concepts and future directions of research on the control of metabolism. In The Control of Metabolism, pp. 225-252 [J. D. Sink, editor]. University Park, PA : Pennsylvania State University Press.

Black, J. L. (1984). The integration of data for prediction of feed intake, nutrient requirements and animal performance. In Herbivore Nutrition in Subtropics and Tropics, pp. 648-671 [F. M. C. Gilchrist and R. J. Mackie, editors]. Craighall, South Africa: Science Press.

Black, J. L., Beever, D. E., Faichney, G. J., Howarth, B. R. \& Graham, N. McC. (1980-1). Simulation of the effects of rumen function on the flow of nutrients from the stomach of sheep. 1 . Descriptions of a computer programme. Agricultural Systems 6, 195-219.

Black, J. L., Campbell, R. G., Williams, I. H., James, K. J. \& Davies, G. T. (1986). Simulation of energy and amino acid utilisation in the pig. Research and Development in Agriculture 3, 121-145.

Brown, R. F. (1980). The identifiability of nonlinear compartmental models. In Identification and System Parameter Estimation, Proceedings of the 5th International Federation of Automatic Control Symposium, pp. 727-734 [R. Isermann, editor]. Oxford: Pergamon Press.

Canolty, N. L. \& Cain, T. P. (editors) (1985). Proceedings of the 1985 Conference on Mathematical Models in Experimental Nutrition. Athens, GA: University of Georgia Press.

Christensen, H. N. (1975). Biological Transport, 2nd ed. Reading, MA: W. A. Benjamin.

Christie, W. W. (editor) (1981). Lipid Metabolism in Ruminant Animals. Oxford: Pergamon Press.

Church, D. C. (1970). Digestive Physiology and Nutrition of Ruminants, vol. 1. Corvallis, OR: D. C. Church.

Corbelli, C. \& Mari, A. (1983). Validation of mathematical models of complex endocrine-metabolic systems: a case study on a model of glucose regulation. Medical and Biological Engineering and Computing 21, $390-399$.

Corbelli, C., Pacini, G. \& Salvan, A. (1980). On a simple model of insulin secretion. Medical and Biological Engineering and Computing 18, 457-463.

Crabtree, B. \& Newsholme, E. A. (1987). The derivation and interpretation of control coefficients. Biochemical Journal 247, 113-120.

Dawson, J. M., Buttery, P. J., Beever, D. E. \& Gill, M. (1989). Effect of carcass manipulation on muscle collagen. Animal Production 48, 657 Abstr.

Draper, N. R. \& Smith, H. (1981). Applied Regression Analysis, 2nd ed. New York: John Wiley \& Sons.

Fioramonti, J. \& Bueno, L. (1988). Hormonal control of gut motility in ruminants and non-ruminants and its nutritional implications. Nutrition Research Reviews 1, 169-188.

France, J., Gill, M., Thornley, J. H. M. \& England, P. (1987). A model of nutrient utilization and body composition in beef cattle. Animal Production 44, 371-386.

France, J. \& Thornley, J. H. M. (1984). Mathematical Models in Agriculture. London: Butterworths.

Garfinkel, D. \& Heinmets, F. (1969). Application of computers to the study of protein metabolism. In Mammalian Protein Metabolism, vol. 3, pp. 263-324. [H. N. Munro, editor]. New York: Academic Press.

Garlick, P. J. (1980). Protein turnover in the whole animal and specific tissues. In Protein Metabolism, Part 2. Comprehensive Biochemistry vol. 19B, pp. 77-152 [A. Neuberger and L. L. M. Vandeenen, editors]. Amsterdam: Elsevier Publishing Co.

Gill, M. (1984). Modelling the partition of nutrients for growth. In Modeling Ruminant Digestion and Metabolism, Proceedings of the 2nd International Workshop, pp. 75. 79 [R. L. Baldwin and A. C. Bywater, editors]. Davis, CA: University of California Press.

Gill, M. (1986). Dynamic models: their use in understanding and predicting nutrient response. Proceedings of the Nutrition Society 45, 221-229.

Gill, M., France, J., Summers, M., McBride, B. W. \& Milligan, L. P. (1989a). Mathematical integration of protein metabolism in growing lambs. Journal of Nutrition (In the Press.)

Gill, M., France, J., Summers, M., McBride, B. W. \& Milligan, L. P. (1989b). Simulation of the energy costs associated with protein turnover and $\mathrm{Na}^{+}, \mathrm{K}^{+}$-transport in growing lambs. Journal of Nutrition 119 (In the Press.)

Gill, M., Thornley, J. H. M., Black, J. L., Oldham, J. D. \& Beever, D. E. (1984). Simulation of the metabolism of absorbed energy-yielding nutrients in young sheep. British Journal of Nutrition 52, 621-649.

Graham, N. McC., Black, J. L., Faichney, G. J. \& Amold, G. W. (1976). Simulation of growth and production in sheep. Model 1. A computer program to estimate energy and nitrogen utilisation, body composition and empty liveweight change day by day for sheep of any age. Agricultural Systems 1, 113-138. 
Greco, W. R. (1986). The role of simulation in biomathematical modeling. Bulletin of Mathematical Biology 48, 241-251.

Groen, A. K., Van der Meer, R., Westerhoff, H. V., Wanders, R. J. A., Akerboom, T. P. M. \& Tager, J. M. (1982). Control of metabolic fluxes. In Metabolic Compartmentation, pp. 9-37 [H. Sies, editor]. London: Academic Press.

Heidegar, W. J. \& Ferguson, M. E. (1985). A theoretical model for calcium absorption from the intestinal rumen. Journal of Theoretical Biology 114, 657-664.

Heinrich, R., Rapoport, S. M. \& Rapoport, T. A. (1977). Metabolic regulation and mathematical models. Progress in Biophysics and Molecular Biology 32, 1-82.

Higgins, J. J. (1965). Dynamics and control in cellular reactions. In Control of Energy Metabolism, pp. 13-46 [B. Chance, R. W. Estabrook and J. R. Williamson, editors]. New York: Academic Press.

Kacser, H. \& Burns, J. A. (1973). The control of flux. In Rate Control of Biological Processes. Symposium of Society for Experimental Biology no. 27, pp. 65-104. Cambridge : Cambridge University Press.

Kootsey, J. M. (1986). Future directions in computer simulation. Bulletin of Mathematical Biology 48, $405-415$. Lewis, A. J. \& Speer, V. C. (1973). Lysine requirement of the lactating sow. Journal of Animal Science 37, $104-110$.

Licko, V. (1973). Threshold secretory mechanism: a model of derivative element in biological control. Bulletin of Mathematical Biology 35, 51-58.

Lindsay, D. B. (1983). Growth and fattening. In Nutritional Physiology of Farm Animals pp. 261-313. [J. A. F. Rook and P. C. Thomas, editors]. London: Longman.

Lister, D. (1989). Muscle metabolism and animal physiology in the dark cutting condition. In Dark Cutting in Cattle and Sheep, Proceedings of an Australian Workshop, pp. 19-25. (S. U. Fabiansson, W. R. Shorthose and R. D. Warner, editors). Sydney: Meat and Livestock Research and Development Corporation, Report 89/2.

Lobley, G. E., Milne, V., Lovie, J. M., Reeds, P. J. \& Pennie, K. (1980). Whole body and tissue protein synthesis in cattle. British Journal of Nutrition 43, 491-S02.

Longland, A. C., Close, W. H. \& Low, A. G. (1989). The role of the large intestine in influencing the use of fibrous feeds by pigs. In Energy Metabolism of Farm Animals, Proceedings of the 11th Symposium, European Association of Animal Production Publication no. 43, pp. 111-114. [Y. van der Honing \& W. H. Close, editors]. Wageningen: Pudoc.

Lunn, P. G., Whitehead, R. G. \& Baker, B. A. (1976). The relative effects of a low-protein high-carbohydrate diet on the free amino acid composition of liver and muscle. British Journal of Nutrition 36, 219-230.

McAllan, A. B., Cockburn, J. E., Williams, A. P. \& Smith, R. H. (1988). The degradation of different protein supplements in the rumen of steers and the effects of these supplements on carbohydrate digestion. British Journal of Nutrition 60, 669-682.

McNurlan, M. A., Tomkins, A. M. \& Garlick, P. J. (1979). The effect of starvation on the rate of protein synthesis in rat liver and small intestine. Biochemical Journal 178, 373-379.

MacRae, J. C. \& Lobley, G. E. (1982). Some factors which influence thermal energy losses during the metabolism of ruminants. Livestock Production Science 9, 447-456.

Mahler, H. R. \& Cordes, E. H. (1971). Biological Chemistry, 2nd ed. New York: Harper and Row.

Mercer, L. P., Flodin, N. W. \& Morgan, P. H. (1978). New methods for comparing the biological efficiency of alternate nutrient sources. Journal of Nutrition 108, $1244-1249$.

Milhorn, H. T. (1975). The special challenge of biological control systems. In The Control of Metabolism, pp. 211-224 [J. D. Sink, editor]. University Park, PA: Pennsylvania State University Press.

Milligan, L. P. (1971). Energetic efficiency and metabolic transformations. Federation Proceedings 30, $1454-1458$.

Mogenson, G. J. \& Calaresu, F. R. (1978). Food intake considered from the viewpoint of systems analysis. In Hunger Models, pp. 1-24 [D. A. Booth, editor]. London: Academic Press.

Moughan, P. J. \& Smith, W. C. (1984). Prediction of dietary protein quality based on a model of the digestion and metabolism of nitrogen in the growing pig. New Zealand Journal of Agricultural Research 27, 501-507.

Murphy, M. R. (1984). Modelling production of volatile fatty acid in ruminants. In Modeling Ruminant Digestion and Metabolism, Proceedings of the 2nd International Workshop, pp. 59-62 [R. L. Baldwin and A. C. Bywater, editors]. Davis, CA: University of California.

Newsholme, E. A. \& Start, C. (1973). Regulation in Metabolism. Chichester: John Wiley \& Sons.

Oldham, J. D. \& Emmans, G. C. (1988). Prediction of responses to protein and energy yielding nutrients. In Nutrition and Lactation in the Dairy Cow, pp. 76-96 [P. C. Garnsworthy, editor]. London: Butterworths.

Oltjen, J. W., Bywater, A. C., Baldwin, R. L. \& Garrett, W. N. (1986). Development of a dynamic model of beef cattle growth and composition. Journal of Animal Science 62, 86-97.

Pettigrew, J. E., Gill, M., France, J. \& Close, W. H. (1989). A mathematical model of sow energy and protein metabolism. In Energy Metabolism of Farm Animals, Proceedings of the 1/th Symposium, European Association of Animal Production Publication no. 43, pp. 119-201 [Y. van der Honing and W. H. Close, editors]. Wageningen: Pudoc.

Pirt. S. J. (1975). Principles of Microbe and Cell Cultivation. Oxford: Blackwell Scientific Publications.

Reeds, P. J., Fuller, M. F. \& Nicholson, B. A. (1985). Metabolic basis of energy expenditure with particular reference to protein. In Substrate and Energy Metabolism in Man, pp. 46-57 [J. S. Garrow and W. Halliday, editors]. London: CRC.

Reeds, P. J., Nicholson, B. A. \& Fuller, M. F. (1987). Contribution of protein synthesis to energy expenditure in 
vivo and in vitro. In Energy Metabolism of Farm animals, Proceedings of the IIth Symposium, European Association of Animal Production Publication no. 32, pp. 6-9 [P. W. Moe, H. F. Tyrrell and P. J. Reynolds, editors]. Totowa, N.J.: Rowman \& Littlefield.

Reich, J. G. \& Sel'kov, E. E. (1982). Energy Metabolism of the Cell: a Theoretical Treatise. New York: Academic Press.

Reynolds, C. K. \& Tyrrell, H. F. (1989). Effects of forage to concentrate ratio and intake on visceral tissue and whole body energy metabolism of growing beef heifers. In Energy Metabolism of Farm Animals, Proceedings of Ilth Symposium, pp. 151-154. [Y. van der Honing and W. H. Close, editors]. Wageningen: Pudoc.

Riggs, D. S. (1963). The Mathematical Approach to Physiological Problems. Cambridge, MA : MIT.

Schulz, A. R. (1978). Simulation of energy metabolism in the simple-stomached animal. British Journal of Nutrition 39, $235-254$.

Segel, I. H. (1975). Enzyme Kinetics. New York: John Wiley \& Sons.

Shipley, R. A. \& Clark, R. E. (1972). Tracer Methods for In Vivo Kinetics. New York: Academic Press.

Siems, W., Dubiel, W., Dumdey, R., Muller, M. \& Rapoport, S. M. (1984). Accounting for the ATP-consuming processes in rabbit reticulocytes. European Journal of Biochemistry 134, 101-107.

Simon, H. A. (1962). The architecture of complexity. Proceedings of the American Philosophical Society 106, $467-482$.

Smith, N. E. (1970). Modelling studies of ruminant metabolism. PhD Thesis, University of California.

Stein, W. D. (1986). Transport and Diffusion Across Cell Membranes. Orlando, FL: Academic Press.

Summers, M., McBride, B. W. \& Milligan, L. P. (1988). Components of basal energy expenditure. In Aspects of Digestive Physiology in Ruminants, pp. 257-286 [A. Dobson and M. J. Dobson, editors]. Ithaca, NY: Comstock Publishing Associates.

Ulyatt, M. J., Waghorn G. C., John, A., Reid, C. S. W. \& Monro, J. (1984). Effect of intake and feeding frequency on feeding behaviour and quantitative aspects of digestion in sheep fed chaffed lucerne hay. Journal of Agricultural Science 102, 645-657.

Waghorn. G. C. \& Baldwin, R. L. (1984). Model of metabolite flux within mammary gland of the lactating cow. Journal of Dairy Science 67, 531-544.

Waterlow, J. C., Garlick, P. J. \& Millward, D. J. (1978). Protein Turnover in Mammalian Tissues and in the Whole Body. Amsterdam : North-Holland.

Whittemore, C. T. \& Fawcett, R. H. (1976). Theoretical aspects of a flexible model to simulate protein and lipid growth in pigs. Animal Production 22, 87-96.

Yang, Y. T. \& Baldwin, R. L. (1973). Lipolysis in isolated cow adipose cells. Journal of Dairy Science 56, $366-374$.

Young, V. R. (1980). Hormonal control of protein metabolism, with particular reference to body protein gain. In Protein Deposition in Animals, pp. 167-191. [P. J. Buttery and D. B. Lindsay, editors]. London: Butterworths. 